\title{
Hydrodynamic and Sensory Factors Governing Response of Copepods to Simulated Predation by Balaenid Whales
}

\author{
Alexander J. Werth \\ Department of Biology, Hampden-Sydney College, Hampden-Sydney, VA 23943-0162, USA \\ Correspondence should be addressed to Alexander J. Werth, awerth@hsc.edu
}

Received 29 July 2011; Accepted 3 February 2012

Academic Editor: Bruce Leopold

Copyright () 2012 Alexander J. Werth. This is an open access article distributed under the Creative Commons Attribution License, which permits unrestricted use, distribution, and reproduction in any medium, provided the original work is properly cited.

Predator/prey interactions between copepods and balaenid (bowhead and right) whales were studied with controlled lab experiments using moving baleen in still water and motionless baleen in flowing water to simulate zooplankton passage toward, into, and through the balaenid oral cavity. Copepods showed a lesser escape response to baleen and to a model head simulating balaenid oral hydrodynamics than to other objects. Copepod escape response increased as water flow and body size increased and was greatest at distances $\geq 10 \mathrm{~cm}$ from baleen and at copepod density $=10,000 \mathrm{~m}^{-3}$. Data from light $/$ dark experiments suggest that escape is based on mechanoreception, not vision. The model head captured $88 \%$ of copepods. Results support previous research showing hydrodynamic effects within a whale's oral cavity create slight suction pressures to draw in prey or at least preclude formation of an anterior compressive bow wave that could scatter or alert prey to the presence of the approaching whale.

\section{Introduction}

Balaenid (bowhead, Balaena mysticetus, and right, Eubalaena spp.) whales (Cetacea: Mysticeti) feed almost exclusively on large aggregations of tiny (1-8 mm total body length) calanoid copepods using continuous ram hydraulic filtration $[1,2]$. Unlike balaenopterid (rorqual, including blue, fin, and humpback) and eschrichtiid (gray) whales that use complex foraging behaviors to accumulate, engulf, and process prey from a single mouthful of seawater, balaenid morphology and ecology is as specialized and constrained as their diet: they merely exploit (by swimming through) existing zooplankton patches [3]. They ingest a steady, unidirectional current of prey-laden water that enters the mouth anteriorly, through a subrostral gap between paired racks of baleen, and then passes through or along the keratinous baleen plates (with approximately 250-350 plates on each side) comprising the filtering apparatus (Figure 1) [1, 4]. Filtered water exits the oral cavity lateral to the pharyngeal orifice, just anterior to the eyes, at the trailing edge of each lip. The enormous, scoop-shaped head, which can measure $1 / 4$ to $1 / 3$ of an adult balaenid whale's $13-18 \mathrm{~m}$ body length, continually removes prey from water as a tow net does, although it is not pulled but rather propelled by the whale's forward locomotion (at all levels of the water column, including surface and benthic layers) at feeding speeds of $2-9 \mathrm{~km} \mathrm{~h}^{-1}$ [5].

Whereas intermittently filtering whales commonly consume large invertebrates (e.g., euphausiids) or fish, an estimated $90 \%$ or more of the balaenid diet (depending on whale species, stock, and feeding grounds) consists of tiny copepods (Arthropoda: Maxillopoda) with $0.5-5 \mathrm{~mm}$ prosome (cephalothorax) and $1-8 \mathrm{~mm}$ total body length and $<0.01$ $0.02 \mathrm{~mL}$ volume [3] as revealed by stomach content and observation/net sampling studies [6]. Balaenid predators are thus 50 billion times larger than their prey and ingest up to $500 \mathrm{~kg}$ of calanoid copepods per day [3,7], primarily Calanus finmarchicus (along with C. glacialis and Pseudocalanus spp.) in North Atlantic right whales, Eubalaena glacialis [7, 8], and C. hyperboreus in bowheads [6], with small amounts of other zooplankton taxa, including principally euphausiids, mysids, and hyperiid and gammarid amphipods [6]. Because balaenid whales feed near the bottom of the trophic pyramid in this abbreviated ecological web, they reap benefits of plentiful energy and biomass, allowing them to attain massive size. However, unlike other large aquatic vertebrates that skim zooplankton via ram hydraulic filtration, including whale 


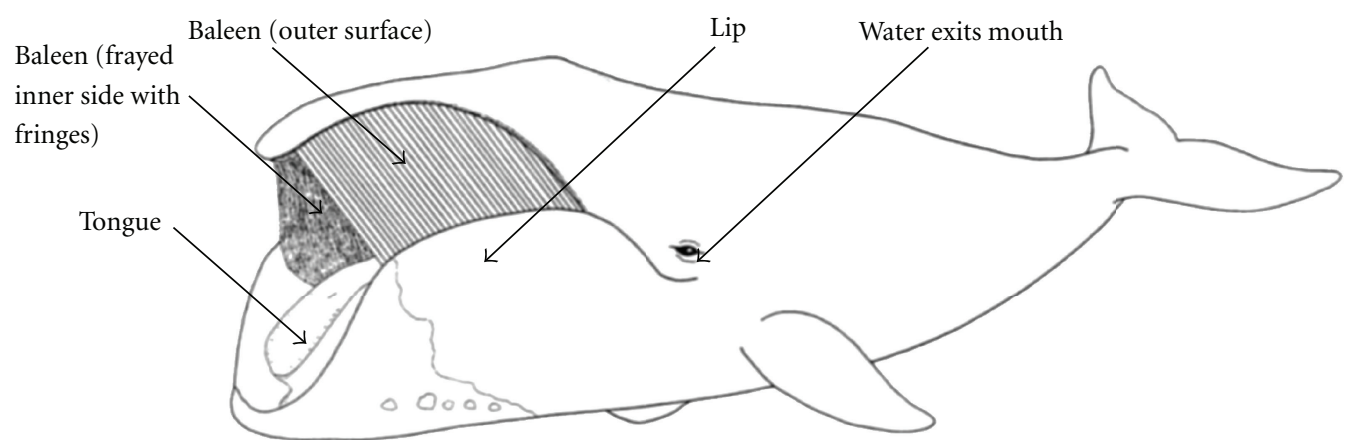

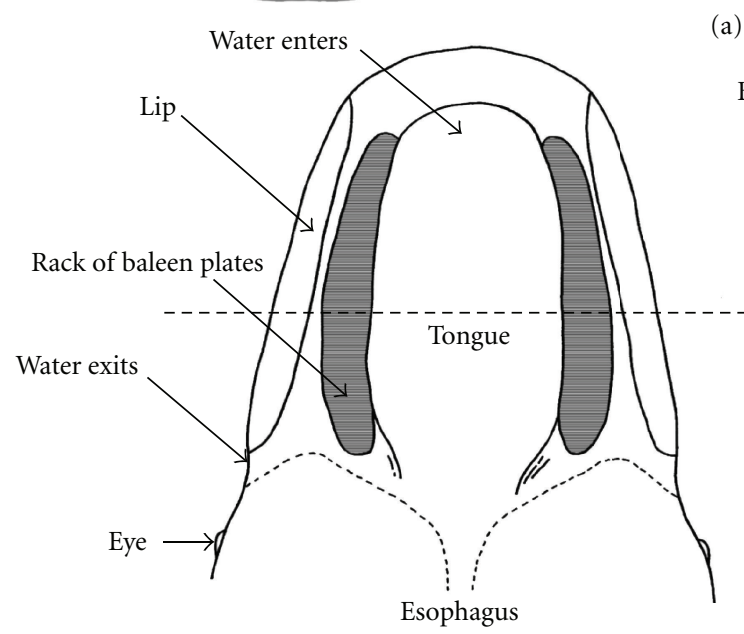

(b) (a)

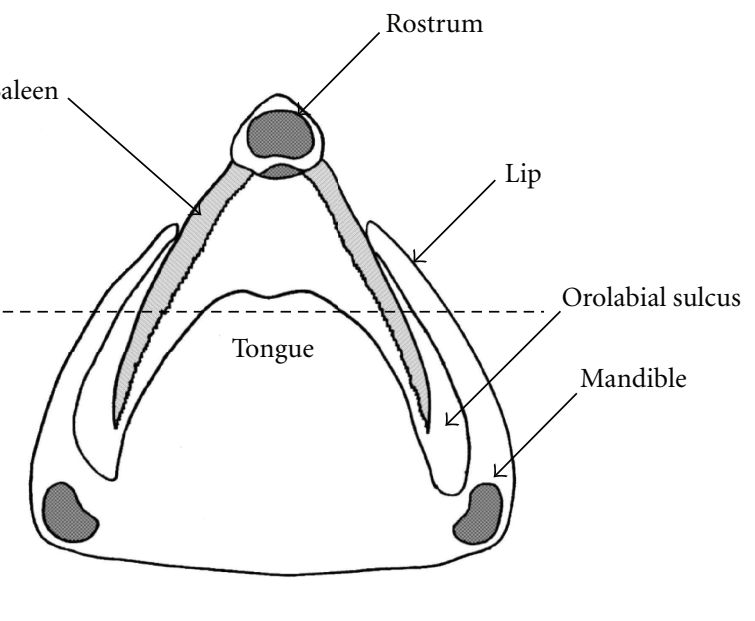

(c)

Figure 1: Schematic diagrams showing external (a) internal (b), and (c) morphology of the oral region and associated structures in a bowhead whale, Balaena mysticetus. At lower left (b) is a frontal section (anterior at top) and at lower right (c) a transverse section (dorsal at top), each at the level of the dashed horizontal line intersecting the other diagram. Prey-laden water enters the mouth anteriorly through a subrostral cleft (between baleen racks) and flows through and around the baleen plates and fringes, exiting, after prey have been removed, behind the lips.

and basking sharks and manta rays, these mammals must sustain a high endothermic metabolic rate, fueled over an annual cycle by alternating periods of feeding and fasting, often of six months each (though the winter fast is typically shorter in E. glacialis) [1, 3].

Balaenids are believed to choose copepods as prey for their abundance as well as their oil content and resulting caloric value [9]. There is evidence that copepod stocks affect right whale calving rates and timing $[3,10,11]$. Although bowhead and right whales must engulf huge volumes of copepods, they are constrained more by the density than sheer abundance of copepods, which exhibit an escape response [12-14]. It is therefore essential for optimal foraging that balaenid prey be compacted into dense patches. Engaging and propelling their filter of exceptionally long (up to $4.6 \mathrm{~m}$ in Balaena and $2.7 \mathrm{~m}$ in Eubalaena), springy, finely fringed baleen (with porosity similar to a $0.333 \mathrm{~mm}$ plankton net [15]) creates substantial drag forces [5]. To optimize caloric intake yet minimize energetic drag costs, balaenids should open their mouths and feed as quickly and efficiently as possible. They have been observed to begin and terminate feeding bouts based on copepod patch density [3], and may alter foraging behavior (notably locomotor speed and thus hydrodynamics of oral filtration) when forced to prey on larger, more mobile, and evasive zooplankton such as Euphausia superba [16]. Balaenids face an enormous challenge of locating an energy-rich yet unreliable, scattered resource-sufficient aggregations of tiny prey that are asymmetrically distributed, temporally and spatially, in highly localized patches throughout a vast ocean-and judging when to open and close their mouths to optimize prey intake, as well as ensuring that prey patches remain concentrated and do not scatter before or during feeding bouts $[3,5]$. This is especially crucial when considering that the baleen filter, with its mat of frayed, hair-like filaments, is a passive ram filter that traps items indiscriminately based on the filtration capacity of the baleen plates and fringes, the abundance and density of prey, and the avoidance behavior, if any, of prey species [15].

A previous experimental study of steady-state hydrodynamic forces encountered during balaenid whale foraging [5] focused on pressure effects accompanying the forces and flows of predation on zooplankton. Mathematical and physical modeling (the latter using a 1/15 scale model in a flow tank with pressure transducers) based on morphometric data obtained from bowhead whales harvested by Inupiat 
Eskimos revealed that unique features of balaenid oral construction and baleen (subrostral gap, orolabial sulcus, baleen rack curvature, extensive mandibular rotation, and lingual mobility) not only permit unidirectional flow through the mouth, but also establish small-scale pressure effects that improve filtering efficiency. Constriction at the posterior of the pipe-like oral cavity increases fluid flow rate while holding volume of flow constant (as a garden hose nozzle increases flow velocity). This Bernoulli effect in turn generates lower intraoral pressure, producing a Venturi effect, with suction pressures measured at $1300-2000 \mathrm{~Pa}(10-20 \mathrm{~mm} \mathrm{Hg})$ [5]. Significantly, this suction is presumed not only to enhance filtration but also to preclude formation of an anterior compressive bow wave that might alert and scatter nektonic or planktonic prey. These pressure effects likely produce sufficient suction anterior to the oral opening to draw in copepods or other minute prey, or at least to prevent their escape. However, effects of such hydrodynamic influences on actual prey items have not previously been tested.

This biomechanical/ecological study focused on predator/prey interactions between copepods and balaenid whales with controlled lab experiments investigating water flow using a variety of experimental setups (based on morphological data) rather than observation of whales and zooplanktonic prey in their natural habitat. A flow tank (flume) simulated passage of prey-laden water toward, into, and through a portion of the mysticete oral cavity, with motionless baleen and flowing water (at variable flow velocity and volume flow rate); to better recreate a swimming whale, moving baleen was tested in still water. Kinematic sequences were recorded in standard and high-speed video in natural light and in darkness (via laser-induced particle image velocimetry or PIV) to analyze and quantify individual and collective movements of prey items. Studies have investigated movements of individual and aggregated copepods but without the presence of feeding whales [17-20] or have looked at balaenid whales swimming through prey, recording data via digital tags (with hydrophones, depth recorders, and accelerometers) $[21,22]$ to explore the relationship between whale locomotion and prey engulfment, but without investigating reactions of prey. Crittercams have been used for rorqual lunge feeding to note changes in body position (roll, pitch, and yaw), jaw opening, or other large-scale and sudden events $[23,24]$, but this is not feasible with right or bowhead whales. Cameras deployed on the back of a feeding balaenid can visualize little due to the tiny size of copepods and great density of their aggregations; cameras used in this way cannot resolve individual prey items or record their movements. Further, none of these approaches offers empirical data on forces, flows, and other events within the whale mouth or addresses ecological questions concerning prey response to whale foraging.

The chief question addressed by this study was (1) how do zooplankters respond to hydrodynamic (flow and pressure) effects simulating an approaching or engulfing whale? In addition, this study asked (2) how does balaenid whale oral flow affect predation on zooplankton? These questions were addressed by flow experiments based on analysis of morphometric and morphological (gross and microscopic) data from the whale mouth. In summary, this study explored a pair of related ecological issues: how can copepods best avoid becoming prey? How can whales best improve their utilization of this resource?

\section{Materials and Methods}

2.1. Experimental Subjects. Samples of bowhead baleen from multiple plates were used for flow tank testing; additional gingival and lingual tissues were examined to test hypotheses of sensory abilities impacting whale foraging ecology. Baleen samples were kept submerged in flowing water for at least seven days prior to testing in all trials. All specimens were obtained from adult whales hunted by Inupiat Eskimos of Barrow, Alaska. Tissues were collected under Permit no. 519 issued to T. F. Albert of the North Slope Borough (Alaska) Department of Wildlife Management by the National Marine Fisheries Service. Additional morphometric data, regarding oral dimensions of adult and juvenile whales relating to foraging mechanics and ecology, were taken from previously published studies [5]. No right whale tissues were used; baleen from Balaena and Eubalaena differs only in plate length, not in fringe number, length, density, or porosity [2].

Initial trials performed to test logistical "proof of concept" (not included in results presented here) used water fleas (Daphnia magna) in fresh water and brine shrimp (mixed Artemia spp.) in artificial seawater. Experimental trials used live marine pelagic calanoid copepods: Calanus finmarchicus (some captured from North Atlantic Ocean, others cultured in lab in pure and artificial seawater at $19^{\circ} \mathrm{C}$ ) and Acartia tonsa (some captured from Gulf of Mexico, others cultured in lab). All swam freely, untethered, and unobstructed. Individual copepods used in experiments were in adult and C3-C5 copepodite stages; attempts were made to remove all naupliar larvae from samples placed into testing tanks, and no kinematic/flow data were recorded from the few nauplii that were observed in film sequences. Adult copepods ranged in total body length from 0.9 to $2.7 \mathrm{~mm}$, with mean total lengths of $1.6 \mathrm{~mm}(N=50, \mathrm{SD}=0.14)$ for $A$. tons $a$ and $1.8 \mathrm{~mm}(N=50, \mathrm{SD}=0.19)$ for $C$. finmarchicus. Copepods of the two genera were tested separately, not mixed together. Copepods were transferred from holding tanks with finemesh nets and put into testing tanks in varying densities ranging from 100 to 50,000 individuals $\mathrm{m}^{-3}$. No attempts were made to separate male, and females, but care was taken to exclude copepod food (phytoplankton) and debris when transferring copepods to testing tanks.

2.2. Flow and Still Tank Testing. Two methods were used to simulate movement of a whale's oral cavity relative to a patch of copepods. In both cases, eight baleen sections (each $20 \mathrm{~cm}$ long $\times 7 \mathrm{~cm}$ wide, not including free fringes) were secured by clamping to a metal rod, creating a miniature "rack" of baleen that was submerged just below the surface of the water, with the plates spaced $1 \mathrm{~cm}$ apart (as in vivo). For the first set of experiments, the baleen filtration apparatus was mounted in a 90-liter circulating flow tank, modeled on a design by Vogel [25]. The tank was made of PVC in a vertical 
loop with a transparent Plexiglas top in which a completely flat viewing window was installed and through which a ruled grid behind the test chamber could be seen. The working section had a length of $70 \mathrm{~cm}$ and cross-sectional area of $900 \mathrm{~cm}^{2}$ (15\% blockage due to the tissue samples, with the rod of baleen attached to the top rim of the testing chamber). Flow through the tank could be adjusted by using impellers of different diameter, by selecting five motor speeds, and with a rheostat to alter input voltage to the motor. Flow velocity for the testing varied from 5 to $140 \mathrm{~cm} \mathrm{~s}^{-1}$; most trials were performed at flow velocities ranging from 10 to $100 \mathrm{~cm} \mathrm{~s}^{-1}$, which accords with locomotor velocity of foraging right and bowhead whales [6, 26-28]. Flow velocity was calibrated before and after experimental trials with a digital flow meter (Geopacks model MFP51; Hatherleigh, Devon, UK).

To examine how water flow from the flow tank (flume) was affecting copepod movements, spacing, and interaction with baleen, all trials were duplicated with the same baleen "rack" moving in still water through a patch of copepods (again, with density varying from 100 to 50,000 individuals $\mathrm{m}^{-3}$ ). Because the working section of the flow tank was too small to accommodate this movement for more than a few seconds, "still water trials" were performed in a $303 \mathrm{~L}$ aquarium ( $125 \mathrm{~cm}$ long), with baleen moved manually at speeds equaling water flow in the flume tank (verified via video by time analysis of baleen movement past a ruled grid suspended behind the tank). In some trials, most copepods were lower in this tank's water column than the baleen plates/fringes could reach; data from such trials were not used in the analysis.

In both flowing and still water (with, respectively, motionless and moving baleen "racks"), steady-state, laminar water flow was achieved, as revealed by seeding the water with reflective, neutrally buoyant $\left(1 \mathrm{~g} \mathrm{cc}^{-1}\right)$ polymer microspheres with a mean particle size (diameter) of $710 \mu \mathrm{m}$. Additional trials tested the influence of other (nonbaleen) submerged objects on copepod orientation and movement. For one set of trials, three items were used (in both $90 \mathrm{~L}$ flow tank and 303 L still tank): a sheet of plastic the same size as a section of bowhead baleen $(20 \times 7 \times 0.5 \mathrm{~cm})$, a hollow plastic box $(18 \times 10 \times 2.5 \mathrm{~cm})$, and the same box filled with water. The second set of nonbaleen trials used a detailed 1/15 scale physical model head of a bowhead whale used in an earlier study of balaenid foraging hydrodynamics [5]. The model was made of synthetic plastic clay over an armature of wire, wood, and foam, with paired racks of "baleen" (300 plates each) made of pliable 18 mil high-density polyethylene; it has variable gape, positioned in this study at normal feeding gape ( $20 \%$ of body length). Like the other objects, it was both mounted in the working chamber of the flow tank as well as propelled (suspended on monofilament line) through the large tank of motionless water. Again, care was taken to avoid turbulent flow.

2.3. Kinematic Analysis. In all series of experiments (both flowing and still tank), the "behavior" (spacing, movement, interaction) of copepods relative to baleen fringes was recorded and analyzed. Kinematic sequences were videotaped from the clear viewing window as well as underwater from the testing chamber itself with a digital recording endoscope (VideoFlex SD; Umarex-Laserliner, Arnsberg, Germany) with an illuminated $17 \mathrm{~mm}$ camera head $(5 / 25 / 50 \mathrm{~cm}$ focal distances) that recorded AVI video and JPEG still images. Digital sequences $(N=328)$ were downloaded and analyzed on a Dell Optiplex 745 or Dell Dimension D10 computer using Kinovea 0.8 .15 video chronometer and motion analysis software. Sequences were analyzed mainly to detect and measure movement of the zooplankton relative to the stationary or approaching baleen. Principal kinematic variables include copepod locomotor velocity, acceleration, turning radius, and movement of buoyant particles, all tracked relative to observational references (fixed grid background or baleen), with playback at 10$100 \%$ of original speed or frame-by-frame, synchronized to time coding. The software allowed for magnification, plane perspective, tracking of path distance, and velocity measurement, which was applied to whole copepods and the baleen fringes/plates/racks or other objects used in flow tank testing.

The camera was mounted in trials using the flow tank, but in trials with moving baleen (or model head or other objects) in the larger tank of motionless water, a fixed camera could not adequately show zooplankton activity. Instead, the camera was moved manually along a track in the same direction and at the same speed as the submerged baleen, such that it could always record, in ambient light or laser illumination, an area of variable distance $(10 \mathrm{~cm}$ or more) from the closest point of the approaching baleen, at which locations the motion of copepods was measured.

"Capture" of copepods by baleen fringes was noted (with copepods deemed captured not when they made incidental contact with baleen but when they remained in contact for at least $3 \mathrm{~s}$ ), but trials were performed mainly to assess movements of the copepods relative to the baleen and to other copepods. Four parameters were varied during the trials, for each genus of copepod: flow velocity $\left(10-140 \mathrm{~cm} \mathrm{~s}^{-1}\right)$, copepod patch density, water temperature $\left(10-29^{\circ} \mathrm{C}\right)$, and illumination. Half the trials were performed in natural and artificial light (with and without additional illumination needed from the videocamera system), and half were performed in total darkness to remove visual cues from the copepods' environment. In the dark trials, particle image velocimetry (PIV) was used to analyze copepod movement [18-20], with laser light illumination using a green laser $(532 \mathrm{~nm}, 1 \mathrm{~W}$, $\mathrm{Nd}$ : $\mathrm{YAG} / \mathrm{Nd}: \mathrm{YVO}_{4}$ ) and lens/mirror arrangement to create a single vertical or horizontal plane of green illumination. (It is unknown if Calanus or Acartia can sense green light, but this is unlikely [29]; in any event, copepods were illuminated by the laser sheet but baleen was not, so copepods could not see it.) For all trials, the water had reflective, neutrally buoyant $\left(1 \mathrm{~g} \mathrm{cc}^{-1}\right)$ polymer microspheres. High-speed digital videorecordings of the illuminated and dark (PIV) trials were analyzed to study movement of the copepods and/or of the reflective particles. In non-PIV (i.e., illuminated rather than laser lit) trials, these neutrally buoyant particles were used to provide a scale to measure dimensions of individual copepods; a ruled background with a $1 \times 1 \mathrm{~cm}$ grid (some squares further ruled into $\mathrm{mm}$ ) also provided for measurement of copepod movement and copepod size. 


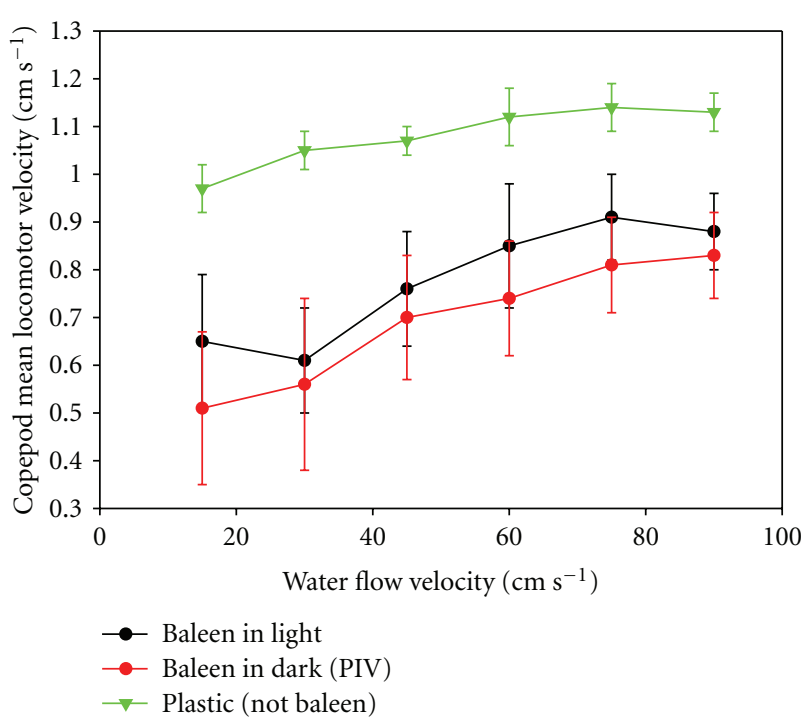

Figure 2: Copepod (Calanus) locomotor velocity (mean, $N=50$; error bars $=1 \mathrm{SD}$ ) in flow tank, measured at distance $=10 \mathrm{~cm}$ from closest baleen, in light and dark (22 degrees $\mathrm{C})$.

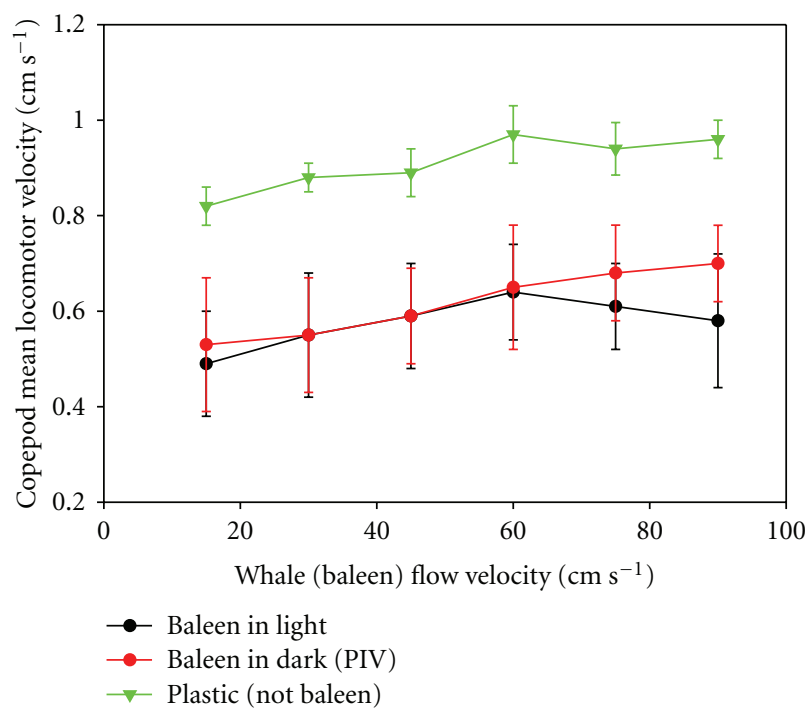

Figure 3: Copepod (Calanus) locomotor velocity (mean, $N=35$; error bars = 1SD) in "still" tank, measured at $10 \mathrm{~cm}$ distance from closest point of moving baleen, in light and dark (22 degrees $\mathrm{C}$ ).

\section{Results}

3.1. General Response of Copepods to Baleen. Copepods demonstrated an escape response to approaching baleen. This occurred in flow tank testing, with copepods moving relative to fixed baleen (Figure 2), and also in tests involving baleen moving relative to copepods (Figure 3); one-way ANOVAs showed no statistical difference $(P=0.42)$ between tests with fixed and moving baleen. The escape response was occasionally observed in isolated copepods moving/scattering in various directions, but more often involved an apparently coordinated response with most (61\%) copepods visible in videotaped sequences moving in roughly the same direction. This direction was sometimes $(<45 \%$ of trials) but not exclusively away from (ahead of and below) the approaching baleen, but almost as often (38\% of trials) involved movement (beyond that of mere water flow, as indicated by the motion of neutrally buoyant particles in the water column) along with or even toward baleen. Although copepods could often be seen tracking in a general, steady direction over the course of several seconds, individual movements took them in various directions, as if tacking back and forth over an alternating course along a general heading. It was possible to analyze locomotor velocities for copepods moving in water in both light and dark (laser lit) conditions, in the latter case using movement of neutrally buoyant beads suspended in the water for particle image velocimetry, and in light using a ruled background (with beads of known dimension also aiding velocity calculation), with peak velocities sustained for up to $2.5 \mathrm{~s}$.

Trials that involved objects other than the "minirack" of actual baleen tissue (in both the $90 \mathrm{~L}$ flow tank and the $303 \mathrm{~L}$ stationary tank) produced a greater response than did the baleen. The plastic sheet (same dimensions as baleen, but without its hair-like fringes or bristles), hollow plastic box, and solid (water-filled) plastic box all triggered movements in the copepods that mostly ( $>75 \%$ of instances) involved copepods swimming away from the objects more rapidly (Figures 2 and 3), more directly (i.e., in a straighter line away from the object), and in a more coordinated fashion (with more copepods moving in the same direction rather than going off separately). However, the trials that used the 1/15scale model of the head in Balaena did not produce such an exaggerated response; the model whale head, which was designed to replicate the actual continuous, one-way flow through the balaenid oral cavity, generated copepod response behavior that was much less concerted (both slower and less directed) than with the other nonbaleen objects being placed in the flow tank or moved through the still water (Figure 4). Particles were deemed "captured" by the head when they entered it anteriorly (through the gape at the orolabial sulcus between left and right baleen racks) but did not exit the head through the paired openings behind each lip, posterior to the orolabial sulcus within $10 \mathrm{~s}$ (individual copepods were not tracked, but number of copepods entering/exiting the model over time was recorded). A high percentage of copepods were captured (82-95\%, depending on the water/head flow rate; mean $88 \%$ ) by this hydrodynamically correct model, and despite the inherent scaling anomaly (with life-size copepods and a 1/15-scale head), fewer copepods demonstrated an escape response to the model than to the baleen tissue itself, and far fewer copepods reacted to the model head than they did to the approach of another object (the plastic triangle meant to simulate baleen or the plastic box).

All experiments were conducted with either of two pelagic copepod species, Calanus finmarchicus or Acartia tonsa. No statistically significant quantitative differences (with $t$ tests, $t=0.36$, and ANOVA, $P=0.29$ ) or noteworthzy qualitative differences were observed in trials that tested the influence of prey species on behavior. Thus, for a few analyses, such as influence of copepod body length on locomotor 


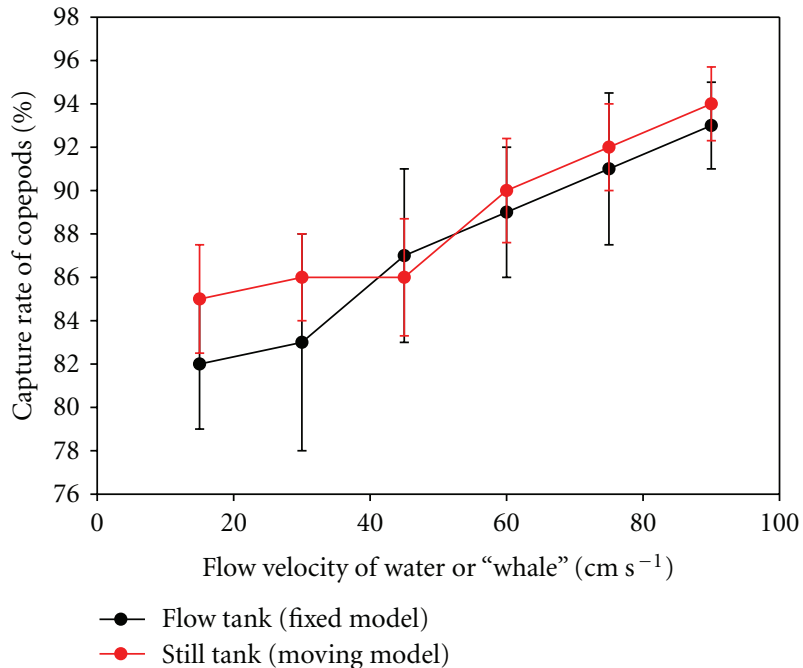

Figure 4: Capture rate of copepods (Acartia) by $1 / 15$-scale physical model of Balaena whale head, including scaled baleen filtering apparatus, in flow and still water tanks (mean, $N=30$; error bars = $1 \mathrm{SD}$; water at 20 degrees C), measured by percentage of copepods observed entering "oral cavity" (on videorecordings) that did not emerge from rear of oral cavity after $10 \mathrm{~s}$.

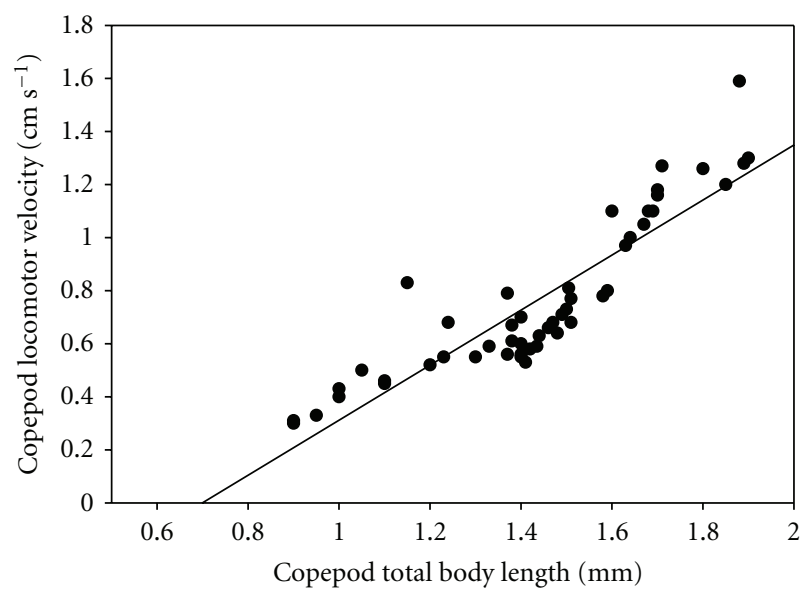

Figure 5: Relation of size versus escape speed in copepods (combined data from Calanus and Acartia) in response to approaching baleen in still tank in light (in water at 20 degrees C).

response (Figure 5), data from Calanus and Acartia were combined. Both species demonstrated similar behaviors with and without the presence of baleen in the water; they remained throughout the water column and did not gather at the surface or bottom, making them ideal experimental subjects. In general, most individuals of both species were able to move away from baleen that was fixed in the flow tank or moving in the still tank; approximately $23 \%$ of copepods overall became entangled in baleen fringes (never $>44 \%$ in any trial).

3.2. Influence of Flow Velocity on Copepod Response. Copepods of both species (C. finmarchicus and A. tonsa) showed more movement and greater locomotor velocity of escape behavior as the flow of water increased (Figure 2), or as the speed of baleen movement in still water similarly increased (Figure 3), with no statistical differences between trials in moving or still water $(P=0.33$ from one-way ANOVA). Likewise, these data did not reveal generally significant differences $(P=0.27)$ as flow rate varied; however, in some cases ( $29 \%$ of all trials), there was statistical significance $(P=0.02)$ as flow velocity increased from 15 to $90 \mathrm{~cm}^{-1} \mathrm{~s}$. Even where there were no statistically significant differences, copepod locomotor velocity showed a general direct correspondence with water flow velocity, with greatest escape velocities recorded with water/baleen flow from 60 to $90 \mathrm{~cm}^{-1} \mathrm{~s}$. As noted above (Section 3.1), copepod locomotor velocities were often sustained for 2-3 s.

3.3. Influence of Light on Copepod Response. The escape response or other movement of the copepods was not found to vary depending on light conditions. The speed, direction, and degree (percentage of individuals in the patch demonstrating movement) of copepod locomotion did not vary whether trials were conducted in natural ambient light or in the dark using laser-illuminated PIV (see Figures 2 and 3). There was slightly more movement of copepods in the light, but statistical ANOVA $(P=0.24)$ and $t$-testing $(t=0.18)$ reveal that these data did not differ significantly from those conducted in darkness.

3.4. Influence of Temperature on Copepod Response. Trials used seawater at temperatures ranging from 4 - to $28^{\circ} \mathrm{C}$. No statistically significant differences whatsoever in copepod behavior were observed as temperature varied $(P=0.48)$. All data presented here show tests at a single temperature.

3.5. Influence of Body Size on Copepod Response. Regression analysis of data showing how copepod locomotor velocity varies according to body length (plotted in Figure 5) indicates that size correlates directly with escape velocity $\left(R^{2}=0.79\right)$. Larger copepods $(1.6-1.9 \mathrm{~mm})$ of both Calanus and Acartia achieved the greatest mean locomotor velocities $\left(1.5-1.7 \mathrm{~cm}^{-1} \mathrm{~s}\right)$.

3.6. Influence of Distance from Baleen on Copepod Response. Another way to investigate copepod escape behavior, in addition to testing effects of the speed of approaching baleen, was to analyze videotapes to examine how distance of copepods from baleen affected their behavior (Figure 6). Video sequences were set up primarily to record copepod behavior at a distance from baleen of $10 \mathrm{~cm}$, but numerous sequences were recorded to test behavior at different distances. At the least baleen "flow velocity" tested (in still tank, with moving baleen, tested in light) of $30 \mathrm{~cm}^{-1} \mathrm{~s}$, copepods showed significantly $(P=0.03)$ slower responses than they did at greater flow speeds (60 and $90 \mathrm{~cm}^{-1} \mathrm{~s}$ ) when the distance from the approaching baleen increased over $10 \mathrm{~cm}$. At this least approach speed, copepod escape velocity rose as baleen got closer and peaked when baleen was 5 or $10 \mathrm{~cm}$ away. At the greater (60 and $90 \mathrm{~cm} \mathrm{~s}^{-1}$ ) approach speeds, there were no significant differences $(P=0.41)$ as distance 


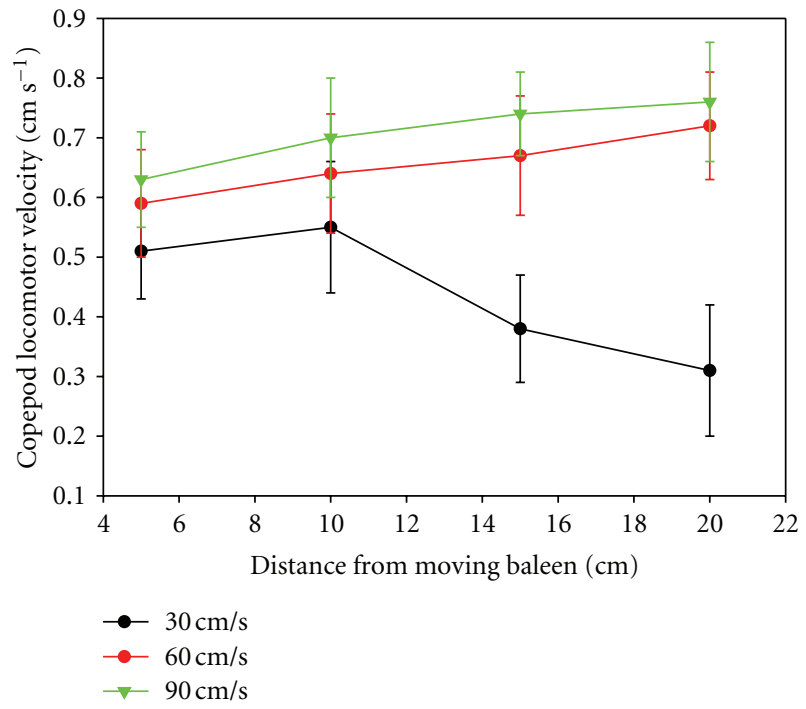

Figure 6: Copepod (Calanus) locomotor velocity (mean, $N=35$; error bars $=1 \mathrm{SD}$ ) in "still" tank, measured at varying distance from closest point of baleen moving at $30-90 \mathrm{~cm} \mathrm{~s}^{-1}$, in light (at 22 degrees $\mathrm{C}$ ).

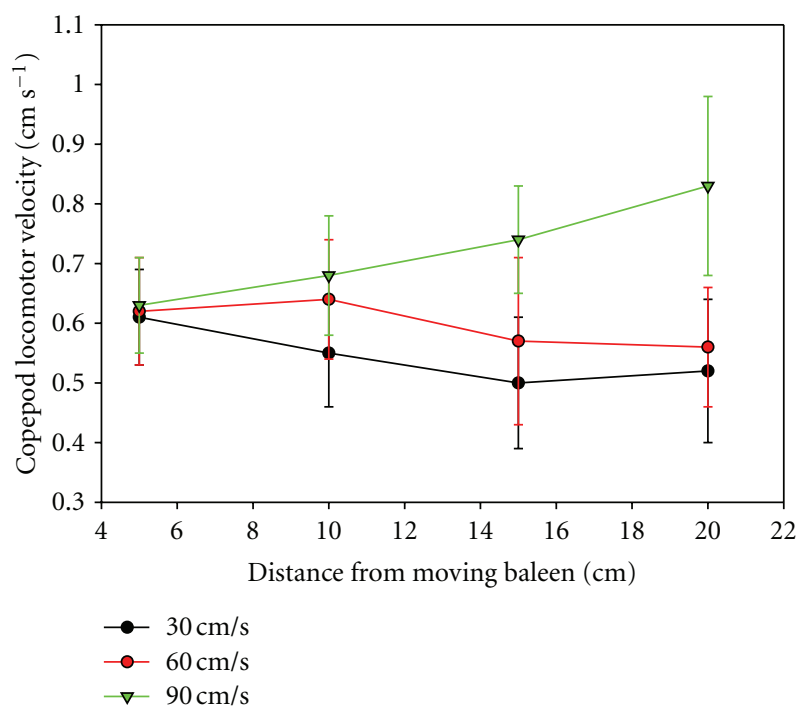

Figure 7: Copepod (Calanus) locomotor velocity (mean, $N=30$; error bars = 1 SD) in "still" tank, measured at varying distance from closest point of baleen moving at $30-90 \mathrm{~cm} \mathrm{~s}^{-1}$, in dark using PIV (at 22 degrees $\mathrm{C}$ ).

decreased (i.e., as baleen got closer), but the copepod locomotor velocity was much greater than it was at the $30 \mathrm{~cm} \mathrm{~s}^{-1}$ approach speed. With the same test done in the dark with PIV (Figure 7), copepods demonstrated the same general response (faster escape velocity as baleen approach speed increased), and the influence of the distance from the baleen was the same as in the lighted test conditions, with copepods showing a heightened escape behavior at greater distances at this greater speed $\left(90 \mathrm{~cm}^{-1} \mathrm{~s}\right)$ than copepods did at the slower speeds ( 30 and $60 \mathrm{~cm} \mathrm{~s}^{-1}$ ). Thus, in both light and dark trials

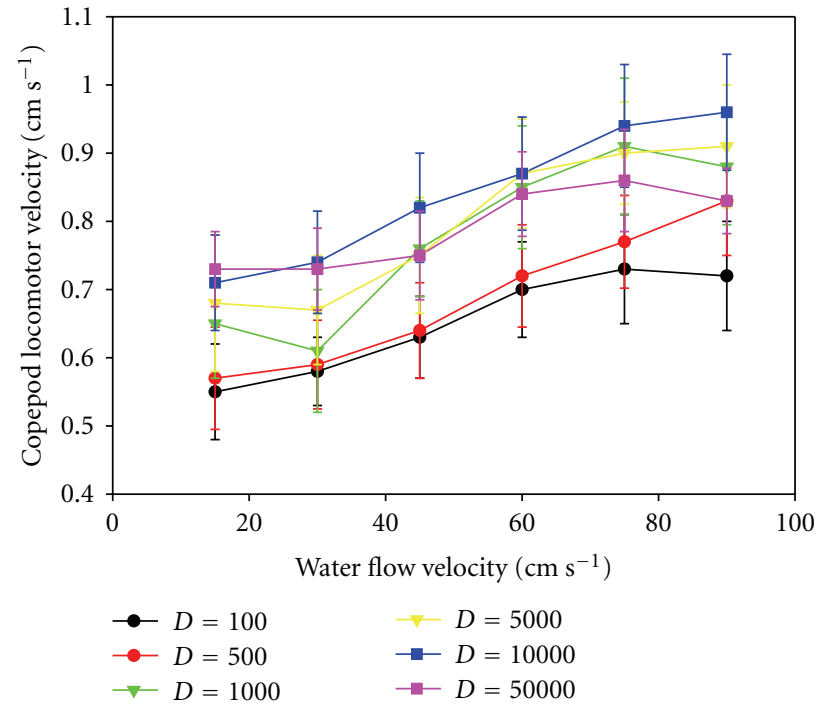

Figure 8: Influence of copepod (Calanus) density on locomotor velocity (mean, $N=35$, error bars $=1 \mathrm{SD}$ ) in flow tank, measured at distance $=10 \mathrm{~cm}$ from closest baleen, in light at 20 degrees $\mathrm{C}$. Density range $=100$ to 50,000 copepods $\mathrm{m}^{-3}$.

(Figures 6 and 7), the distance at which copepods reacted to approaching baleen was dependent on flow rate (=speed of approaching baleen). Copepods at extremely short distances from baleen $(5 \mathrm{~cm})$ did not demonstrate an escape behavior that differed statistically $(P=0.37)$ from those at greater distances $(>5 \mathrm{~cm})$. As noted above, few copepods became captured in the baleen fringe "filter" under the conditions of any experiments.

3.7. Influence of Patch Density on Copepod Response. The final parameter that was studied in these experiments concerned patch density of copepods (Calanus and Acartia, tested under all experimental conditions). As prey patch density increased from 100 to 50,000 individuals per $\mathrm{m}^{3}$, it became increasingly difficult to observe and resolve movements of individual copepods relative to each other and relative to calibrating measures (both the ruled grid behind the tank and buoyant particles in the water), but it is clear that locomotor velocities steadily increase as patch density increases (Figure 8), with significant differences between least (100) and greatest $\left(10,000-50,000\right.$ copepods $\left.\mathrm{m}^{-3}\right)$ densities. The escape response was greatest at patch density of $10,000 \mathrm{~m}^{-3}$ (Figures 8 and 9); this declined as density increased to $50,000 \mathrm{~m}^{-3}$, and one-way ANOVA testing revealed that the difference was statistically significant $(P=0.04$; Figure 9 ).

\section{Discussion}

4.1. General Response of Copepods to Baleen. Calanoid copepods use chemoreception to detect presence and location of their own food (all kinds of phytoplankton as well as microbes and detritus) [13] and have a small eyespot that senses light and darkness, possibly allowing copepods to 


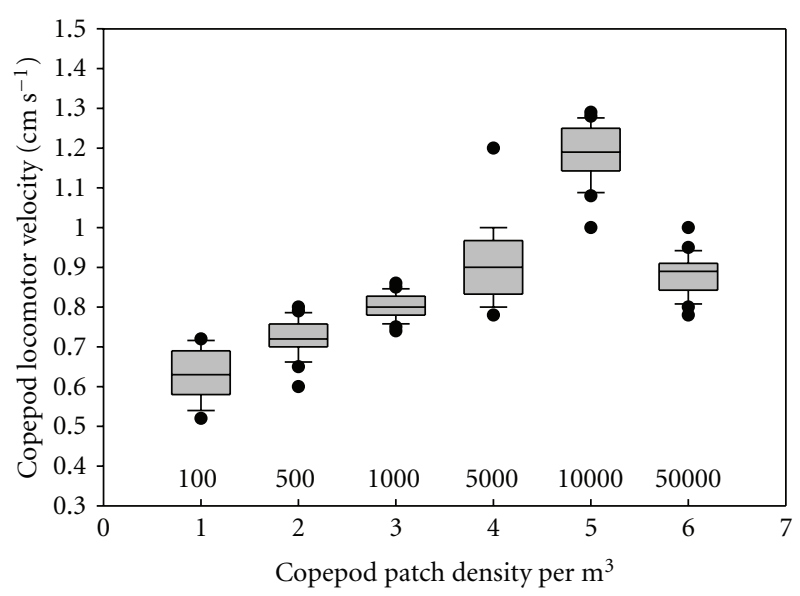

Figure 9: Box-and-whisker plot showing range of copepod (Calanus) locomotor velocity $(N=35$, with median and 25 th and 75th percentiles as edges of box, and whiskers as 10th and 90th percentiles), related to patch density (from 100 to $50 \mathrm{~K} \mathrm{~m}^{-3}$ ), recorded in light, with flow $=60 \mathrm{~cm} \mathrm{~s}^{-1}$, at 20 degrees $\mathrm{C}$.

orient their body and track movement (their own and of other objects) [29]. However, copepods mainly sense environmental changes via mechanoreception, by spreading their long, paired antennae to detect vibrations or current changes in adjacent water $[12,13,30,31]$. Both copepod species tested in this study showed no coordinated movement (motion in the same direction) when on their own in the water, whereas their movements showed coordination when there was baleen or another object nearby and approaching, with the greatest responses observed when the object was 15$20 \mathrm{~cm}$ away (Figures 6 and 7). Both C. finmarchicus and A. tonsa moved more often, more rapidly (Figures 2 and 3 ), and more efficiently (covering the greatest distance) when they were approached by an object rather than by other copepods. Further, they showed significantly greater escape response to nonbaleen objects than to the actual baleen tissue itself (Figures 2 and 3), perhaps because the fine fringes on this filtering material (which were not present on the plastic objects tested) contribute to greater laminar flow and do not generate a compressive anterior "bow wave" that might alert copepods to the pending approach of a potential predator [3033]. The capture of high (82-95) percentages of copepods by the model whale head further supports the conclusion that the hydrodynamic effects previously observed [5], namely, the slight suction pressures generated within the balaenid oral cavity due to Bernoulli and Venturi effects, may also be important in capturing planktonic prey and especially in not alerting such prey to presence of a feeding whale $[5,34]$.

4.2. Influence of Flow Velocity on Copepod Response. The flow velocities tested in this study (both for fixed baleen in the flow tank and moving baleen in the stationary seawater tank) are in accord with those of foraging right and baleen whales [6,26-28]. Although there were slight differences in copepod locomotor velocity (Figures 2 and 3 ) as flow velocity increased, these were not significant, and differences with capture rate of copepods by the scaled model head with changing flow velocity (Figure 4 ) were barely significant at the $P<0.05$ level. Thus, the findings presented here are not sufficiently conclusive to address the question of how whale swimming speed will affect prey response. However, given that increased flow velocity (representing a faster swimming whale) did lead to slightly greater escape response by copepods, and especially considering that drag forces from continuous filtration increase substantially as a whale's locomotor velocity increases (as a square of the velocity) [5], it may tentatively be concluded that slower swimming speeds ( $1 \mathrm{~m} \mathrm{~s}^{-1}$ or less) may be optimal for balaenid whales foraging on copepods, provided no other influences (e.g., currents) are dispersing the plankton.

4.3. Influence of Light on Copepod Response. Calanoid copepods (including both species tested in this study) display a diel vertical migration [35] by altering the density of lipid stores to modulate buoyancy $[36,37]$ that is presumed to hide them (in deeper, darker water) from predators during daylight hours and allow them to track food sources that may migrate vertically $[38,39]$. However, results of this experimental study do not show a difference in copepod behavior in light versus dark environmental conditions, suggesting that the escape response or other reaction to approaching baleen does not depend on vision, either in sighting or otherwise sensing the approaching baleen (or entire whale) or in seeing escape behavior of other, nearby copepods. This supports the conclusion that copepod escape behavior is not visually based but depends on hydrodynamic disturbance. What are the consequences for balaenid foraging ecology? Balaenid whales are most often observed feeding during daylight hours and sleeping (if seen at all) at night, though this likely relates to limitations of human observers. Given the diel vertical migrations of copepods, it is expected that right whales feed at night $[35,37,40]$; furthermore, day/night distinctions may not be meaningful during much of the year for an arctic species such as the bowhead. It is not known how right and bowhead whales locate patches of prey at the surface or at any depth in the water column, but vision is one possibility that has been suggested $[37,41]$. If it is true that balaenids use eyesight to locate presence and margins of a patch, and possibly its density, then it appears that bright daylight will not limit ability of whales to forage optimally on this resource, as these data indicate that copepods will not be more prone to scatter in light, decreasing patch density and hence the whale's foraging efficiency, due to their own visual sensation of an approaching whale or baleen filter.

4.4. Influence of Temperature on Copepod Response. Ambient water temperature was not shown to have any effect on copepod behavior in these experiments simulating balaenid filter feeding. Neither normal copepod locomotion nor response to approaching baleen or other objects was affected in any way by temperature (i.e., copepods did not swim more slowly in cold). Most balaenid feeding occurs at high latitudes during the summer feeding season, with bowheads foraging principally on arctic copepods (Calanus hyperboreus) [6] and 
all species of right whale, the Southern (Eubalaena australis), North Atlantic (E. glacialis), and North Pacific (E. japonica), also feeding on cold-water copepods [3, 13, 42, 43]. However, data from satellite-linked transmitters [44] and from stable isotope ratios in baleen [45] suggest that bowheads feed during winter in the Beaufort and Chukchi Seas. Results of this study do not indicate that temperature will make any difference either to copepods in sensing presence of feeding whales or for the foraging whales themselves.

4.5. Influence of Body Size on Copepod Response. Larger copepods (i.e., of longer total body length) showed a significantly greater swimming speed and heightened (faster) escape response to approaching baleen (Figure 5). Given that large patches of copepods and other planktonic prey upon which whales feed include mixed aggregations of different age classes [7, 46], and sometimes species [3, 47, 48], it should make little or no difference for whales seeking to find the densest aggregations of prey. However, from an ecological standpoint, it may be that younger, smaller copepods are more easily captured and hence removed from a population by foraging whales than are older, larger copepods, or that species with smaller body sizes are likewise more easily preyed upon by balaenid whales. It must be emphasized that a determination of whether smaller and more easily captured copepodites are more energetically advantageous prey than larger, more energy-dense [9] yet more elusive copepod age classes and species would require a detailed energetic analysis beyond the scope of this kinematic study.

4.6. Influence of Distance from Baleen on Copepod Response. Because of water's incompressibility, the bow wave generated by a moving whale (if any, given that hydrodynamic effects within the mouth are likely sufficient to cancel such a wave) [5] would be felt by organisms that can sense pressure differences, as can many zooplankton, including calanoid copepods. Findings of these experiments show that at least speed $\left(30 \mathrm{~cm} \mathrm{~s}^{-1}\right)$, copepods showed the greatest response when baleen was $5-10 \mathrm{~cm}$ away (Figure 6), with one-third less escape velocity at greater distances. At greater flow (=whale swimming) speeds, however, copepod swimming velocity rose as distance increased (although this difference was not significant), perhaps because they were alerted to presence of the oncoming baleen by its own compressive force, or by the escape of other copepods. Limited trials showed that there was no coordinated or faster than normal movement at distances from the baleen of greater than $40 \mathrm{~cm}$. No studies in nature have been conducted to investigate at what distance from an actual whale copepods or other zooplankton might initiate an escape response, so this is wholly unknown, but results of these laboratory experiments indicate that at the normal foraging speed of right and bowhead whales (2-9 $\mathrm{km} \mathrm{hr}^{-1}$, or $\left.0.5-2.5 \mathrm{~m} \mathrm{~s}^{-1}\right)$, these distances are almost certainly too small for prey to make any effective escape, with the possible exception of more evasive zooplankton such as larger euphausiids $[49,50]$, which are occasionally but only rarely taken by balaenids [16]. Balaenids have been observed feeding on elusive prey while swimming at high speeds, however; Hamner et al. [16] reported an account of southern right whales foraging on krill while swimming at 10 knots.

4.7. Influence of Patch Density on Copepod Response. In all conditions tested, copepods displayed a greater response (higher locomotor velocity, presumably of escape response) at greater patch densities, and with significantly greatest response at a density of 10,000 individuals $\mathrm{m}^{-3}$ (Figure 9). This may be because as some individuals move in response to the approaching baleen, other copepods sense their movements and are warned to flee. However, it is also possible that increased speeds of copepod movements at greater patch density are due merely to the high number of copepods in a relatively small, enclosed space, with no effect from the simulated predation (i.e., approaching object). Although variable prey densities were tested in this controlled lab setting, copepods were typically in less dense aggregations than have often been measured near feeding right and bowhead whales [7, 46, 47]. Copepods can of course be feeding while they are likewise being fed upon by whales, such that their patch density may depend likewise on abundance and density of phytoplankton [51]. (It was not the case in this study that copepods were moving to collect phytoplankton, which were not placed with copepods in the test chambers.) Still, patch density of copepods and other small zooplankters obviously depends mainly on currents and other oceanographic conditions [52]. However, whereas dense patches afford the most energetic benefit and least energetic (drag) cost for whales feeding via continuous ram filtration, the data from this study indicate that copepods in dense patches are also most likely to display high locomotor velocities that potentially indicate an escape response. This is significant because such patches might disperse to a lesser density and hence become less optimal resources for feeding whales. Yet it is unlikely that the escape response of copepods is fast enough to appreciably scatter patch densities, especially over the scales of times and distances and times needed to affect foraging right or bowhead whales.

\subsection{General Conclusions Concerning Balaenid Foraging Ecolo-} gy and Predation on Copepods. Balaenids are limited by speed and elusiveness of their prey. Copepods are weak swimmers that aggregate only where permitted by currents or other conditions, but this study confirmed that copepods can swim by flicking their antennae for short times (5-10 s) and distances $(10-15 \mathrm{~cm})$ at sustained speeds around $1 \mathrm{~cm} \mathrm{~s}^{-1}$, or over several millimeters in single strokes $[20,31]$. To ensure optimal foraging by balaenid whales, movement of a single copepod, however fast or slow, is less important than that of an aggregation with billions to trillions of copepods $[7,53]$ remain tightly packed.

This study focused on predator/prey interactions between copepod aggregations and balaenid whale filtering tissues using controlled lab experiments (based on morphological analysis) rather than observation of whales and planktonic prey in their natural habitat. Although the simple experimental design involved a different physical scope 
than a whole whale and full-size patch of zooplankton, it is nevertheless novel and important because it tested aggregations of free-swimming copepods interacting with actual baleen tissue and recorded movements of individual copepods reacting to these conditions of simulated predation. A $2 \mathrm{~mm}$ copepod and a $20 \mathrm{~m}$ whale occupy vastly different scales, with a difference in Reynolds number of a billion orders of magnitude, from $10^{-1}$ in the copepod to $10^{8}$ in the whale [25], but their lives are inextricably linked. Previous laboratory studies of copepod locomotor kinematics have used tethered [54] or free single copepods in chambers of stationary water, and it is known that calanoid copepods flee from various stimuli including shadows, currents, and pressure waves that indicate the approach of a predator [12, $30,31,55]$. Although copepods and other zooplankton are known to avoid nets $[56,57]$, observers of feeding whales report no bow waves or other hydrodynamic phenomena $[47,58]$ that would alert or scatter prey.

Likewise, these experiments demonstrated no remarkable hydrodynamic effects from the simulated predation (using baleen tissue and the model head) and little or no consequent response from copepods. Although the plastic sheet and box (hollow and water-filled) showed a distinct compressive wave when moved through water or fixed in the flow tank, as revealed by movement of copepods and especially of buoyant particles, the actual baleen (in miniracks and individually, the latter not used in results here) and model head did not. Instead, particle motion was not disrupted by flow of water toward the baleen/head or by forward motion of the baleen/head through the water. The genuine in vivo balaenid filtering apparatus (Figure 1) consists of two racks of 250-350 full-size (up to $4.6 \mathrm{~m}$ ) plates [59, 60], whereas this study used ex vivo smaller collections of eight "plates," each section representing a mere $5 \%$ of the length of a real baleen plate. Still, it was instructive to deploy these miniature racks of multiple plates, as copepods often managed to escape the first or second plate of the rack but were swept into more posterior baleen. This is likely how the model head was able to capture so many copepods (nearly 90\%), when individual copepods in kinematic sequences were observed avoiding baleen fringes. The ability of the filamentous baleen fringes, and the entire frayed mat they comprise, to sustain laminar flow and to create, based on curvature of the racks plus other oral dimensions, Venturi and other hydrodynamic effects $[5,34]$ cannot be discounted. This study focused on copepod reactions to baleen, but ongoing experiments are being conducted to determine baleen porosity under varying conditions, and to visualize precise directions of water flow relative to individual plate margins and fringes [61].

It has been estimated that feeding right whales consume 400,000-4,000,000 Calories (or the equivalent of 0.26-26 billion copepods, and between 0.6 and $6.4 \%$ of the whale's body weight) per day [53]. How much a whale actually consumes depends on zooplankton concentration: regions with abundant prey may be unsuitable due to their widely dispersed nature, whereas locations with smaller patches of extremely concentrated prey can yield high volumes of ideally distributed food sources. From a sample of dense copepods $\left(331,000\right.$ copepods $\left.\mathrm{m}^{-3}\right)$ taken immediately beside a feeding right whale, Beardsley et al. [7] estimated that the whale was ingesting 1.4 billion copepods $\mathrm{hr}^{-1}$. Balaenids are slow swimmers with a simple, stereotyped foraging mechanism and no repertoire of diverse behaviors (as other whales have), but they have been observed to adjust their precise vertical position and to make sharp turns in response to horizontal clines in prey abundance, so that they optimize foraging by remaining in a path offering the highest potential concentrations of prey items [47], something that rorquals (Balaenopteridae), which are much faster yet feed via lunges and wide turns, are unable to do [58,62].

How do right and bowhead whales locate copepods and other zooplankton? How do they gauge density of plankton patches? How do they judge where and when best to open and close the mouth? Given their urgent metabolic need to locate and consume dense patches of prey, and indeed the finding that the densest plankton patches ever recorded have been associated with feeding whales [7, 63], Baumgartner et al. [3] ruled out random prospecting. Rather, depending on the scope of the geographic scale, from thousands of kilometers to mere centimeters, these whales likely use a variety of methods, including searching for specific bathymetric contours or topographic landmarks (e.g., seamounts), or perhaps by sensing currents or upwelling or by navigating to known feeding grounds (from instinct, learning, or both) with solar, geomagnetic, or other environmental cues $[64,65]$. It is possible that they forage cooperatively, relying on conspecifics to find and relay (actively or passively, intentionally or inadvertently) information on dense sources of prey [3]. At very short distances, whales likely use their own immediate senses to detect prey presence and perhaps also prey density [64]. As with the copepods themselves, foraging whales may use vision or chemosensation (olfaction and gustation are reduced but not absent in balaenids [66, 67], so chemical cues from prey could be detected), but right and bowhead whales probably rely on mechanoreception via the few, scattered hair follicles on the head [68] or with other sensors such as Pacinian and Meissner's corpuscles and free nerve endings. The dermis and subdermis of the balaenid tongue [69] and palatal rete [70] also have sufficient neural networks to relay data from mechanical stimulation, and the vascular systems of these organs, featuring countercurrent blood flow [69], could easily vasodilate to enhance mechanical sensitivity at low water temperatures [71].

Balaenids feed at all levels of the water column, including the surface and benthic layers, with no known differences in prey, in hydrodynamics, or in foraging behavior. The sole difference is that preys at the surface and bottom are restricted by an upper or lower limit on their distribution, whereas midwater prey can be widely distributed vertically [3], although they may also be condensed by oceanographic factors. For example, North Atlantic right whales foraging in the Bay of Fundy have been observed to feed on a dense layer of prey vertically aggregated at the density interface along the upper surface of the bottom mixed layer [8]. Trapping prey at the sea surface would be an effective way for balaenid whales to condense their prey and thus maximize foraging efficiency, though this increases the potential for ship strikes or other collisions $[40,72]$. There is evidence of copepods aggregating 
near the sea floor $[3,34]$, where active and abandoned fishing gear and lines are sometimes located, thereby creating risks of entanglement [73, 74]. Because balaenid whales are so rigidly adapted morphologically and behaviorally to capturing copepods, these already highly endangered whales are even more vulnerable to extinction when such entanglements occur or should plankton stocks decline due to oceanographic/ecological conditions or human impact.

The past decade has witnessed extraordinary advances in our understanding of mysticete foraging ecology, with data from digital tags deployed on feeding whales providing detailed information on the links between whale locomotion and prey engulfment [22-24], but they tell us nothing about the hydrodynamic forces and flows within the whale mouth. In the continued absence of in vivo intraoral data, hopefully to be remedied by placement of tags within the mouth or with swallowed prey, our best approximation of such forces and flows comes from functional morphology and biomechanical investigations of mysticete tissues, especially baleen, tested under controlled conditions presumed to be as realistic as possible. Given that such ex vivo tissue studies have not previously been attempted, the study presented here, despite its manifest limitations, advances considerably our understanding of balaenid whale ecology and biomechanics.

\section{Acknowledgments}

Samples of baleen are from animals harvested by Inupiat hunters of the Alaska Eskimo Whaling Commission in accordance with their exemption to the U.S. Marine Mammal Protection Act and other national and international restrictions. The author is grateful to these hunters for allowing him to examine and sample their whales. Tissues were collected under Permit no. 519 issued to T. F. Albert of the North Slope Borough (Alaska) Department of Wildlife Management by the National Marine Fisheries Service. He is indebted to I. Robertson for construction of the flow tank, and to S. Vogel for advice on its design. He thanks all his students who assisted with data collection. Numerous constructive comments from anonymous reviewers greatly improved the quality of this paper. Discussions about right and bowhead whale foraging with M. Baumgartner, J. C. George, R. Suydam, R. Payne, C. Mayo, S. Kraus, A. Knowlton, T. Ford, and other scientists also provided valuable information and ideas.

\section{References}

[1] A. J. Werth, "Feeding in marine mammals," in Feeding: Form, Function, and Evolution in Tetrapod Vertebrates, K. Schwenk, Ed., pp. 487-526, Academic Press, San Diego, Calif, USA, 2000.

[2] A. J. Werth, "How do mysticetes remove prey trapped in baleen?" Bulletin of the Museum of Comparative Zoology, vol. 156, pp. 189-203, 2001.

[3] M. F. Baumgartner, C. A. Mayo, and R. D. Kenney, "Enormous carnivores, microscopic food, and a restaurant that's hard to find," in Urban Whale: North Atlantic Right Whales at the
Crossroads, S. D. Kraus and R. M. Rolland, Eds., pp. 138-171, Harvard University Press, Cambridge, Mass, USA, 2007.

[4] A. Pivorunas, "The feeding mechanisms of baleen whales," American Scientist, vol. 67, no. 4, pp. 432-440, 1979.

[5] A. J. Werth, "Models of hydrodynamic flow in the bowhead whale filter feeding apparatus," Journal of Experimental Biology, vol. 207, no. 20, pp. 3569-3580, 2004.

[6] L. F. Lowry, "Foods and feeding ecology," in The Bowhead Whale, J. J. Burns, J. J. Montague, and C. J. Cowles, Eds., pp. 201-238, Society for Marine Mammalogy, Lawrence, Kan, USA, 1993.

[7] R. C. Beardsley, A. W. Epstein, C. Chen, K. F. Wishner, M. C. Macaulay, and R. D. Kenney, "Spatial variability in zooplankton abundance near feeding right whales in the Great South Channel," Deep-Sea Research II, vol. 43, no. 7-8, pp. 1601-1625, 1996.

[8] M. F. Baumgartner and B. R. Mate, "Summertime foraging ecology of North Atlantic right whales," Marine Ecology Progress Series, vol. 264, pp. 123-135, 2003.

[9] G. C. Laurence, "Caloric values of some North Atlantic calanoid copepods," Fishery Bulletin, vol. 74, pp. 218-220, 1976.

[10] R. D. Kenney, "Right whales and climate change: facing the prospect of a greenhouse future," in The Urban Whale: North Atlantic Right Whales at the Crossroads, S. D. Kraus and R. M. Rolland, Eds., pp. 436-459, Harvard University Press, Cambridge, Mass, USA, 2007.

[11] C. H. Greene, A. J. Pershing, T. M. Cronin, and N. Ceci, "Arctic climate change and its impacts on the ecology of the North Atlantic," Ecology, vol. 89, supplement 11, pp. S24-S38, 2008.

[12] L. R. Haury, D. E. Kenyon, and J. R. Brooks, "Experimental evaluation of the avoidance reaction of Calanus finmarchicus," Journal of Plankton Research, vol. 2, no. 3, pp. 187-202, 1980.

[13] L. A. van Duren and J. J. Videler, "The trade-off between feeding, mate seeking and predator avoidance in copepods: behavioural responses to chemical cues," Journal of Plankton Research, vol. 18, no. 5, pp. 805-818, 1996.

[14] L. A. van Duren and J. J. Videler, "Escape from viscosity: the kinematics and hydrodynamics of copepod foraging and escape swimming," Journal of Experimental Biology, vol. 206, no. 2, pp. 269-279, 2003.

[15] C. A. Mayo, B. H. Letcher, and S. Scott, "Zooplankton filtering efficiency of the baleen of a North Atlantic right whale, Eubalaena glacialis," Journal of Cetacean Research and Management Special Issue, no. 2, pp. 225-229, 2001.

[16] W. M. Hamner, G. S. Stone, and B. S. Obst, "Behavior of Southern right whales, Eubalaena australis, feeding on the Antarctic krill, Euphausia superba," Fishery Bulletin, vol. 86, no. 1, pp. 143-150, 1988.

[17] M. J. Morris, G. Gust, and J. J. Torres, "Propulsion efficiency and cost of transport for copepods: a hydromechanical model of crustacean swimming," Marine Biology, vol. 86, no. 3, pp. 283-295, 1985.

[18] E. J. Stamhuis and J. J. Videler, "Quantitative flow analysis around aquatic animals using laser sheet particle image velocimetry," Journal of Experimental Biology, vol. 198, no. 2, pp. 283-294, 1995.

[19] L. A. van Duren, E. J. Stamhuis, and J. J. Videler, "Copepod feeding currents: flow patterns, filtration rates and energetics," Journal of Experimental Biology, vol. 206, no. 2, pp. 255-267, 2003.

[20] H. Jiang and T. Kiorboe, "Propulsion efficiency and imposed flow fields of a copepod jump," Journal of Experimental Bio$\log y$, vol. 214, no. 3, pp. 476-486, 2011. 
[21] M. F. Baumgartner and F. W. Wenzel, "Springtime foraging ecology of North Atlantic right whales," in Proceedings of the Ocean Sciences Meeting, American Geophysical Union and American Society of Limnology and Oceanography, Orlando, Fla, USA, March, 2008.

[22] M. J. Simon, M. Johnson, P. Tyack, and P. T. Madsen, "Behaviour and kinematics of continuous ram filtration in bowhead whales (Balaena mysticetus)," Proceedings of the Royal Society B, vol. 276, no. 1674, pp. 3819-3828, 2009.

[23] J. A. Goldbogen, N. D. Pyenson, and R. E. Shadwick, "Big gulps require high drag for fin whale lunge feeding," Marine Ecology Progress Series, vol. 349, pp. 289-301, 2007.

[24] J. A. Goldbogen, J. Calambokidis, E. Oleson et al., "Mechanics, hydrodynamics and energetics of blue whale lunge feeding: efficiency dependence on krill density," Journal of Experimental Biology, vol. 214, no. 1, pp. 131-146, 2011.

[25] S. Vogel, Life in Moving Fluids: The Physical Biology of Flow 2e, Princeton University Press, Princeton, NJ, USA, 1996.

[26] R. R. Reeves and S. Leatherwood, "Bowhead whale, Balaena mysticetus Linnaeus 1758," in Handbook of Marine Mammals, S. H. Ridgway and R. Harrison, Eds., vol. 3 of The Sirenians and Baleen Whales, pp. 305-344, Academic Press, San Diego, Calif, USA, 1985.

[27] G. M. Carroll, J. C. George, L. F. Lowry, and K. O. Coyle, "Bowhead whale (Balaena mysticetus) feeding near Point Barrow, Alaska, during the 1985 spring migrations," Arctic, vol. 40, pp. 105-110, 1987.

[28] D. P. Nowacek, M. Johnson, P. Tyack, K. A. Shorter, W. A. McLellan, and D. A. Pabst, "Buoyant balaenids: the ups and downs of buoyancy in right whales," Proceedings of the Royal Society $B$, vol. 268, no. 1478, pp. 1811-1816, 2001.

[29] J. H. Cohen and R. B. Forward, "Spectral sensitivity of vertically migrating marine copepods," Biological Bulletin, vol. 203, no. 3, pp. 307-314, 2002.

[30] D. M. Fields and J. Yen, "The escape behavior of marine copepods in response to a quantifiable fluid mechanical disturbance," Journal of Plankton Research, vol. 19, no. 9, pp. 1289-1304, 1997.

[31] E. J. Buskey, P. H. Lenz, and D. K. Hartline, "Escape behavior of planktonic copepods in response to hydrodynamic disturbances: high speed video analysis," Marine Ecology Progress Series, vol. 235, pp. 135-146, 2002.

[32] T. Kiorboe and E. Saiz, "Planktivorous feeding in calm and turbulent environments, with emphasis on copepods," Marine Ecology Progress Series, vol. 122, no. 1-3, pp. 135-145, 1995.

[33] H. Yamazaki and K. D. Squires, "Comparison of oceanic turbulence and copepod swimming," Marine Ecology Progress Series, vol. 144, no. 1-3, pp. 299-301, 1996.

[34] R. H. Lambertsen, K. J. Rasmussen, W. C. Lancaster, and R. J. Hintz, "Functional morphology of the mouth of the bowhead whale and its implications for conservation," Journal of Mammalogy, vol. 86, no. 2, pp. 342-352, 2005.

[35] M. F. Baumgartner, N. S. J. Lysiak, C. Schuman, J. UrbanRich, and F. W. Wenzel, "Diel vertical migration behavior of Calanus finmarchicus and its influence on right and sei whale occurrence," Marine Ecology Progress Series, vol. 423, pp. 167184, 2011.

[36] J. T. Enright, "Copepods in a hurry: sustained high-speed upward migration," Limnology and Oceanography, vol. 22, no. 1, pp. 118-125, 1977.

[37] M. F. Baumgartner, T. V. N. Cole, R. G. Campbell, G. J. Teegarden, and E. G. Durbin, "Associations between North Atlantic right whales and their prey, Calanus finmarchicus, over diel and tidal time scales," Marine Ecology Progress Series, vol. 264, pp. 155-166, 2003.

[38] D. K. Ralston, D. J. Mcgillicuddy, and D. W. Townsend, "Asynchronous vertical migration and bimodal distribution of motile phytoplankton," Journal of Plankton Research, vol. 29, no. 9, pp. 803-821, 2007.

[39] K. Haraguchi, T. Yamamoto, S. Chiba, Y. Shimizu, and M. Nagao, "Effects of phytoplankton vertical migration on the formation of oxygen depleted water in a shallow coastal sea," Estuarine, Coastal and Shelf Science, vol. 86, no. 3, pp. 441-449, 2010.

[40] Woods Hole Oceanographic Institution, "Prey-tell: why right whales linger in the Gulf of Maine," Science Daily, 2012 http:// www.sciencedaily.com/releases/2011/04/110426151042.htm.

[41] Q. Zhu, D. J. Hillmann, and W. G. Henk, "Morphology of the eye and surrounding structures of the bowhead whale, Balaena mysticetus," Marine Mammal Science, vol. 17, no. 4, pp. 729750, 2001.

[42] V. J. Rowntree, L. O. Valenzuela, P. F. Fraguas, and J. Seger, "Foraging behaviour of southern right whales (Eubalaena australis) inferred from variation of carbon stable isotope rations in their baleen," Report of the International Whaling Commission (IWC) SC/60.BRG23, 2008.

[43] W. C. Cummings, "Right whales_Eubalaena glacialis and Eubalaena australis," in Handbook of Marine Mammals, S. H. Ridgway and R. Harrison, Eds., vol. 3 of The Sirenians and Baleen Whales, pp. 275-304, Academic Press, San Diego, Calif, USA, 1985.

[44] L. T. Quakenbush, J. J. Citta, J. C. George, R. J. Small, and M. P. Heide-Jorgensen, "Fall and winter movements of bowhead whales (Balaena mysticetus) in the Chukchi Sea and within a potential petroleum development area," Arctic, vol. 63, no. 3, pp. 289-307, 2010.

[45] S. H. Lee, D. M. Schell, T. L. McDonald, and W. J. Richardson, "Regional and seasonal feeding by bowhead whales Balaena mysticetus as indicated by stable isotope ratios," Marine Ecology Progress Series, vol. 285, pp. 271-287, 2005.

[46] K. F. Wishner, E. Durbin, A. Durbin, M. Macaulay, H. Winn, and R. Kenney, "Copepod patches and right whales in the Great South Channel off New England," Bulletin of Marine Science, vol. 43, no. 3, pp. 825-844, 1988.

[47] C. A. Mayo and M. K. Marx, "Surface foraging behaviour of the North Atlantic right whale, Eubalaena glacialis, and associated zooplankton characteristics," Canadian Journal of Zoology, vol. 68, no. 10, pp. 2214-2220, 1990.

[48] L. D. Murison, Zooplankton distributions and feeding ecology of right whales (Eubalaena glacialis glacialis) in the outer Bay of Fundy, Canada, M.S. thesis, University of Guelph, Guelph, Canada, 1986.

[49] P. F. Brodie, D. D. Sameoto, and R. W. Sheldon, "Population densities of euphausiids off Nova Scotia as indicated by net samples, whale stomach contents, and sonar," Limnology and Oceanography, vol. 23, pp. 1264-1267, 1978.

[50] P. H. Wiebe, C. J. Ashjian, S. M. Gallager, C. S. Davis, G. L. Lawson, and N. J. Copley, "Using a high-powered strobe light to increase the catch of Antarctic krill," Marine Biology, vol. 144, no. 3, pp. 493-502, 2004.

[51] B. T. Hargrave and G. H. Geen, "Effects of copepod grazing on two natural phytoplankton populations," Journal of the Fisheries Research Board of Canada, vol. 27, no. 8, pp. 1395-1403, 1970.

[52] A. W. Epstein and R. C. Beardsley, "Flow-induced aggregation of plankton at a front: a 2-D Eulerian model study," Deep-Sea Research II, vol. 48, no. 1-3, pp. 395-418, 2001. 
[53] R. D. Kenney, M. A. M. Hyman, R. E. Owen, G. P. Scott, and H. E. Winn, "Estimation of prey densities required by western North Atlantic right whales," Marine Mammal Science, vol. 2, no. 1, pp. 1-13, 1986.

[54] K. B. Catton, D. R. Webster, J. Brown, and J. Yen, "Quantitative analysis of tethered and free-swimming copepodid flow fields," Journal of Experimental Biology, vol. 210, no. 2, pp. 299-310, 2007.

[55] R. J. Waggett and E. J. Buskey, "Calanoid copepod escape behavior in response to a visual predator," Marine Biology, vol. 150, no. 4, pp. 599-607, 2007.

[56] R. A. Barkley, "The theoretical effectiveness of towed-net samplers as related to sampler size and to swimming speed of organisms," Journal du Conseil Permanent International pour l'Exploration de la Mer, vol. 29, pp. 146-157, 1964.

[57] P. H. Wiebe, S. H. Boyd, B. M. Davis, and J. L. Cox, "Avoidance of towed nets by the euphausiid Nematoscelis megalops," Fishery Bulletin, vol. 80, no. 1, pp. 75-91, 1982.

[58] W. A. Watkins and W. E. Schevill, "Right whale feeding and baleen rattle," Journal of Mammalogy, vol. 57, pp. 58-66, 1976.

[59] T. Nemoto, "Food of baleen whales with reference to whale movements," Scientific Reports of the Whales Research Institute, vol. 14, pp. 149-291, 1959.

[60] A. Pivorunas, "A mathematical consideration on the function of baleen plates and their fringes," Scientific Reports of the Whales Research Institute, vol. 28, pp. 37-55, 1976.

[61] A. J. Werth, "Flow-dependent porosity of baleen from the bowhead whale (Balaena mysticetus) ," in Proceedings of the Society for Integrative and Comparative Biology, Salt Lake City, Utah, USA, 2011, abstract.

[62] W. A. Watkins and W. E. Schevill, "Aerial observations of feeding behavior in four baleen whales: Eubalaena glacialis, Balaenoptera borealis, Megaptera novaeangliae, and Balaenoptera physalus," Journal of Mammalogy, vol. 60, pp. 155-163, 1979.

[63] K. F. Wishner, J. R. Schoenherr, R. Beardsley, and C. Chen, "Abundance, distribution and population structure of the copepod Calanus finmarchicus in a springtime right whale feeding area in the South Western Gulf of Maine," Continental Shelf Research, vol. 15, no. 4-5, pp. 475-507, 1995.

[64] R. D. Kenney, C. A. Mayo, and H. E. Winn, "Migration and foraging strategies at varying spatial scales in Western North Atlantic right whales: a review of hypotheses," Journal of Cetacean Research and Management Special Issue, no. 2, pp. 251-260, 2001.

[65] M. J. Simon, The sounds of whales and their food: baleen whales, their foraging behavior, ecology and habitat use in an arctic habitat, Ph.D. thesis, Aarhus University, 2010.

[66] J. G. M. Thewissen, J. George, C. Rosa, and T. Kishida, “Olfaction and brain size in the bowhead whale (Balaena mysticetus)," Marine Mammal Science, vol. 27, no. 2, pp. 282-294, 2011.

[67] T. Kishida and J. G. M. Thewissen, "Evolutionary changes of the importance of olfaction in cetaceans based on the olfactory marker protein gene," Gene, vol. 492, no. 2, pp. 349-353, 2012.

[68] J. K. Ling, "Vibrissae of marine mammals," in Functional Anatomy of Marine Mammals, R. J. Harrison, Ed., vol. 3, pp. 387-415, Academic Press, London, UK, 1977.

[69] A. J. Werth, "Adaptations of the cetacean hyolingual apparatus for aquatic feeding and thermoregulation," Anatomical Record, vol. 290, no. 6, pp. 546-568, 2007.

[70] T. J. Ford and S. D. Kraus, "A rete in the right whale," Nature, vol. 359, no. 6397, article 680, 1992.

[71] G. Dehnhardt, B. Mauck, and H. Hyvärinen, "Ambient temperature does not affect the tactile sensitivity of mystacial vibrissae in harbour seals," Journal of Experimental Biology, vol. 201, no. 22, pp. 3023-3029, 1998.

[72] S. E. Parks, J. D. Warren, K. Stamieszkin, C. A. Mayo, and D. Wiley, "Dangerous dining: surface foraging of North Atlantic right whales increases risk of vessel collisions," Biology Letters, vol. 8, no. 1, pp. 57-60, 2012.

[73] A. J. Johnson, S. D. Kraus, J. F. Kenney, and C. A. Mayo, "The entangled lives of right whales and fishermen: can they coexist?" in The Urban Whale: North Atlantic Right Whales at the Crossroads, S. D. Kraus and R. M. Rolland, Eds., pp. 380-408, Harvard University Press, Cambridge, Mass, USA, 2007.

[74] T. Johnson, Entanglements: The Intertwined Fates of Whales and Fishermen, University of Florida Press, Gainesville, Fla, USA, 2005. 

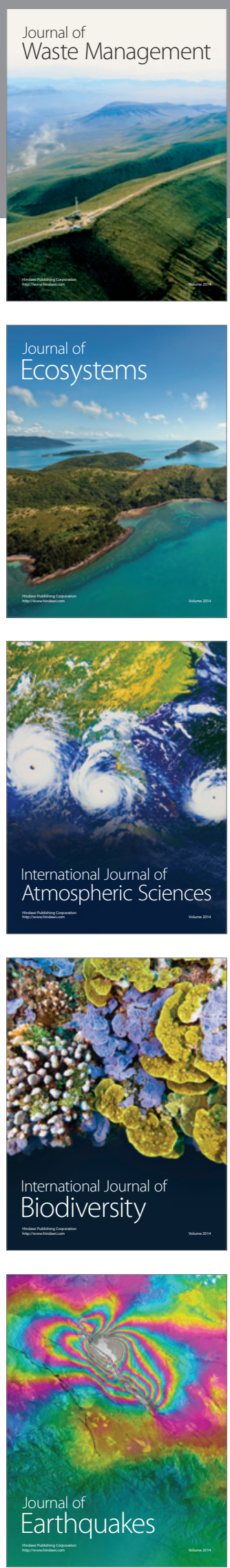
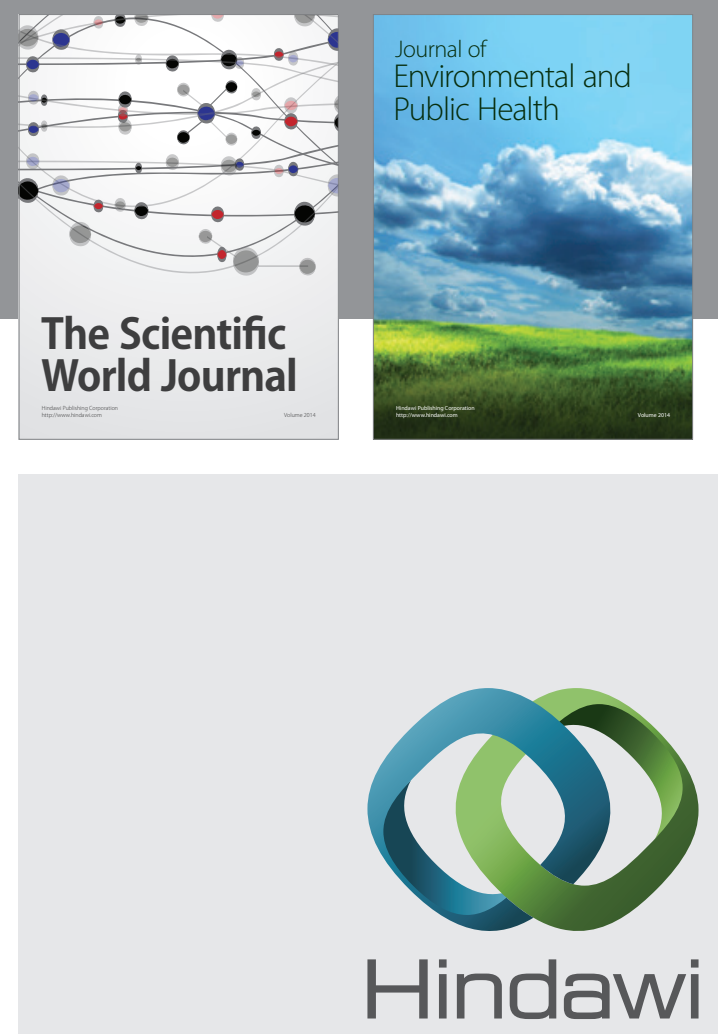

Submit your manuscripts at

http://www.hindawi.com
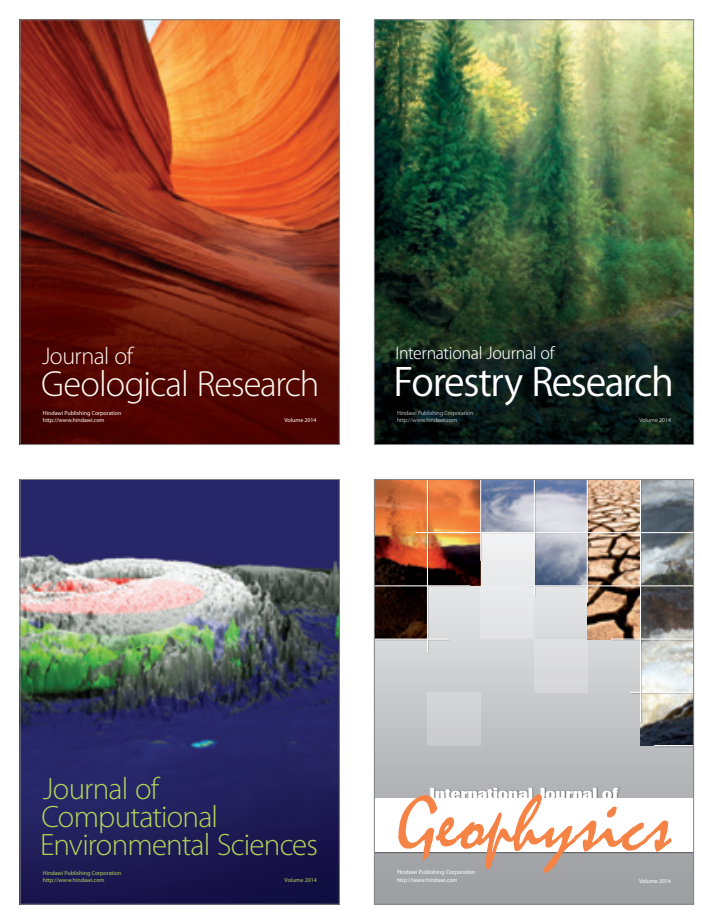
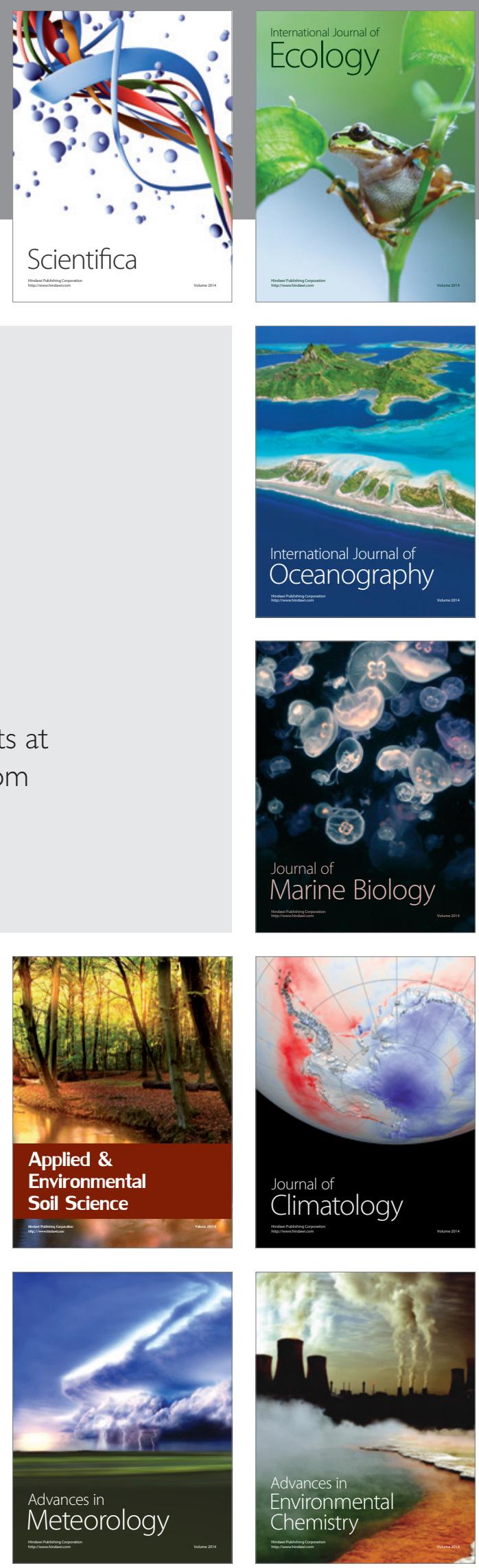